\title{
Penentuan Jarak Antar Tiang Penerangan Jalan UmumUntuk Jalan Lurus dan Jalan Melengkung Pada Jalan Tol Ruas Lingkar Luar Jakarta W2 Utara Seksi I
}

\author{
Ersalia Dewi Nursita'; ${ }^{1}$ Soetjipto Soewono ${ }^{2}$ \\ ${ }^{1,2}$ Institut Teknologi PLN \\ 1ersaliadn@gmail.com
}

\begin{abstract}
The Jakarta Outer Ring Road North W2 Section I has a different road width and also an interchange that is curved like a circle. On this toll road the distance between the piles used in both type of road is the same, that is equal to $30 \mathrm{~m}$. Determination of the distance between the poles of the street lighting for straight roads and curved paths in this thesis using the phytagoras method. Where the distance between the lampposts for a straight road with the width of the road ranges from $4.5 \mathrm{~m}$ to $14.5 \mathrm{~m}$ from the calculation results require the distance between piles of 21.09 to $29.85(<30 \mathrm{~m})$ this results in less lighting standard. And for the width of the road ranging from $15.5 \mathrm{~m}$ to $30.5 \mathrm{~m}$ from the calculation results require the distance between the piles of $31.01 \mathrm{~m}$ to $50.82 \mathrm{~m}$ (>30 m) which results in waste in the installation of the number of poles. Whereas for curved roads with a road width of $7.5 \mathrm{~m}$ for the placement of light poles in the arches of the road requires a smaller distance between piles of $20.96 \mathrm{~m}(<30 \mathrm{~m})$.
\end{abstract}

Keywords: Distance Between Poles, Standard, Toll Road, Strong Lighting

\begin{abstract}
ABSTRAK
Jalan tol ruas Lingkar Luar Jakarta W2 utara seksi 1 memiliki lebar jalan yang berbeda dan juga sebuah interchange yang berbentuk melengkung seperti lingkaran. Pada jalan tol tersebut jarak antar tiang lampu penerangan yang digunakan pada tipe jalan keduanya sama yaitu sebesar $30 \mathrm{~m}$. Penentuan jarak antar tiang penerangan jalan umum untuk jalan yang lurus dan jalan melengkung pada tesis ini menggunakan metode phitagoras. Dimana jarak antar tiang lampu untuk jalan yang lurus dengan lebar jalan berkisar antara 4,5 m sampai 14,5 $\mathrm{m}$ dari hasil perhitungan membutuhan jarak antar tiang sebesar 21,09 sampai 29,85 (<30 m) hal ini mengakibatkan pencahayaan yang kurang dari standar. Dan untuk yang lebar jalan berkisar 15,5 m sampai 30,5 $\mathrm{m}$ dari hasil perhitungan membutuhkan jarak antar tiang sebesar 31,01 $\mathrm{m}$ sampai $50,82 \mathrm{~m}(>30 \mathrm{~m})$ yang mengakibatkan pemborosan dalam hal pemasangan jumlah tiang. Sedangkan untuk jalan yang melengkung dengan lebar jalan sebesar 7,5 m untuk penempatan tiang lampu didalam lengkungan jalan membutuhkan jarak antar tiang yang lebih kecil sebesar 20,96 $\mathrm{m}(<30 \mathrm{~m})$.
\end{abstract}

Kata kunci: Jarak Antar Tiang, Standar, Jalan Tol, Kuat Pencahayaan 


\section{Energi dan Kelistrikan: Jurnal Ilmiah}

Vol. 12, No. 2, Juli - Desember 2020, P-ISSN 1979-0783, E-ISSN 2655-5042

https://doi.org/10.33322/energi.v12i2.1063

\section{PENDAHULUAN}

Pesatnya pertumbuhan pembangunan di Indonesia pada setiap daerah, yang mengacu kepada RKP (Rencana Kerja Pemerintah) 2019 tentang pemerataan pembangunan untuk pertumbuhan yang berkualitas (Bappenas, 2018). Hal tersebut mendorong setiap pemerintah daerah, untuk memperbaiki sarana dan prasarana yang digunakan oleh masyarakat, agar terciptanya pertumbuhan pembangunan yang merata pada setiap daerah.

Pembangunan dan perbaikan infrastruktur jalan sangatlah penting karena dapat meningkatkan konektivitas yang berujung pada pertumbuhan ekonomi yang membaik. Contohnya perbaikan perlengkapan jalan tol dimana jalan tol merupakan suatu solusi yang dikhususkan untuk kendaraan bersumbu lebih dari dua (mobil, bus, truk) yang bertujuan untuk mengurangi kemacetan, mempersingkat jarak, dan waktu tempuh dari satu tempat ke tempat lain, hal ini diperlukan seiring dengan kepadatan aktifitas pemakai jalan. Salah satu perlengkapan jalan yang sangat dibutuhkan adalah Penerangan Jalan Umum untuk penerangan jalan tol dimana tujuan utama dari penerangan jalan tol adalah untuk menghasilkan kekontrasan antara objek dan permukaan jalan, sebagai alat bantu navigasi pengguna jalan, meningkatkan keselamatan dan kenyamanan pengguna jalan khususnya pada malam hari, mendukung keamanan lingkungan, dan memberikan keindahan lingkungan jalan.

Lampu penerangan jalan memiliki standar jarak antar tiang minumum sebesar 30 m (SNI 7391 ; 2008) untuk setiap pemasangan tiang lampu jalan. Hal ini perlu diperhatikan, karena penentuan jarak antar tiang lampu penerangan jalan sangatlah mempengaruhi kualitas penerangan yang diberikan (standar kuat pencahayaan untuk jalan tol 15 - 20 lux (SNI 7391 ; 2008)) selain dari pada itu, apabila penentuan jarak antar tiang lampu penerangan jalan dapat ditentukan dengan baik maka akan dapat menghindari terjadinya penerangan yang tidak sesuai dengan standar pada jalan, sehingga dapat menghemat biaya pengadaan dan konstruksi lampu penerangan jalan.

Dari beberapa permasalahan di atas maka dilakukan pembahasan mengenai penentuan jarak antar tiang lampu penerangan jalan yang sesuai untuk kebutuhan penerangan jalan berdasarkan standar SNI 7391;2008 pada jalan tol Ruas Lingkar Luar Jakarta W2 Utara Seksi I.

\section{METODE PENELITIAN}

\subsection{Lokasi Penelitian}

Penelitian ini mengambil lokasi di jalan tol ruas lingkar luar jakarta W2 utara seksi I dengan panjang jalan sepanjang 920,19 m. Dimana pada jalan tol ini memiliki jalan yang melengkung berupa interchange dan jalan yang lurus namun memiliki lebar jalan yang berbeda-beda.

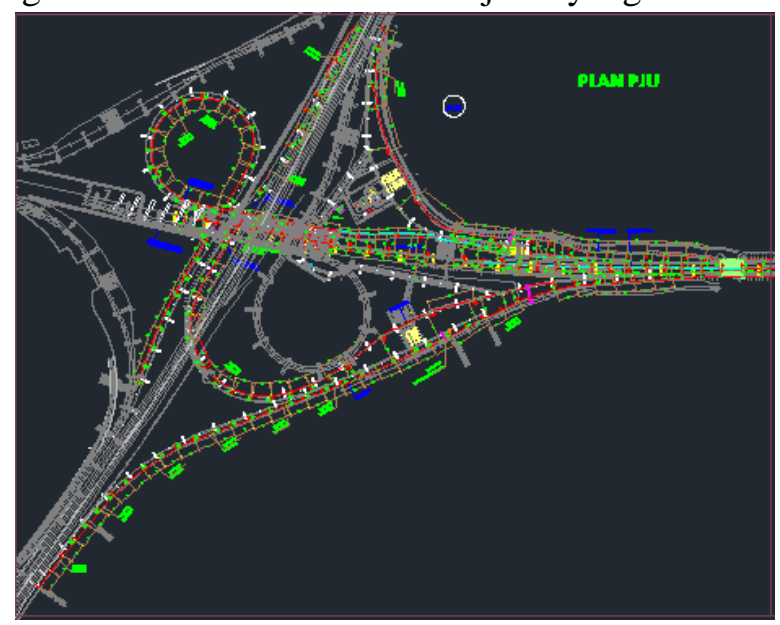

Gambar 1. Peta Jalan Tol 


\subsection{Data-Data Yang Dibutuhkan}

Data-data yang dibutuhkan merupakan data yang diambil dari PT. Marga Lingkar Jakarta (MLJ) seperti gambar dan kondisi lokasi Jalan tol (Lebar jalan dan panjang jalan) dan data standar spesifikasi penerangan jalan tol, yang digunakan dalam tesis ini yaitu SNI 7391 (2008).

\subsection{Metode Penelitian dan Pengumpulan Data}

Metode penelitian yang digunakan pada tesis ini yaitu metode pythagoras dimana metode ini akan dihitung jarak antar tiang berdasarkan kuat pencahayaannya sehingga diperoleh jarak antar tiang yang ideal yang mempengaruhi kualitas pencahayaan lampu jalan tol. Sedangkan untuk metode pengumpulan data digunakan yaitu studi literatur dan studi lapangan, yaitu :

\section{Studi Literatur}

Studi literatur dilakukan upaya mempelajari dan mengumpulkan data untuk menunjang penelitian. Data yang dikumpulkan berasal dari buku referensi, jurnal, dokumen-dokumen standar penerangan yaitu SNI 7391 (2008) dan artikel dari internet yang berkaitan dengan topik tesis ini.

\section{Studi Lapangan}

Studi lapangan merupakan upaya pengumpulan data lapangan yang diperoleh langsung dari pengelola Jalan Tol Lingkar Luar Jakarta W2 utara seksi I yaitu PT. Marga Lingkar Jakarta (MLJ).

\subsection{Penentuan Jarak Antar Tiang}

Dalam penentuan jarak antar tiang digunakan metode trigonometri, berikut hasil penentuan jarak antar tiangnya :

1. Penentuan jarak antar tiang untuk jalan yang lurus

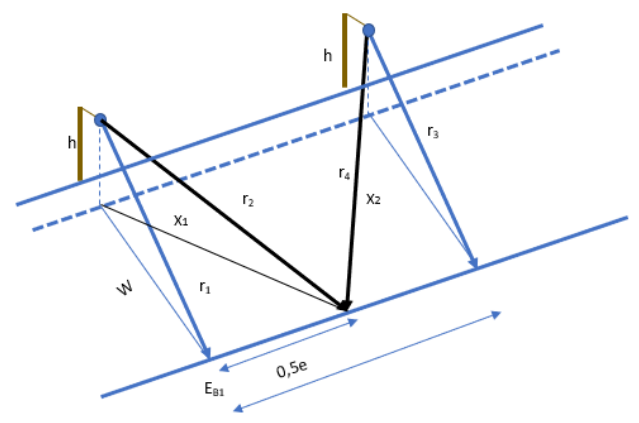

Gambar 2. Perhitungan untuk penentuan jarak antar tiang untuk jalan yang lurus

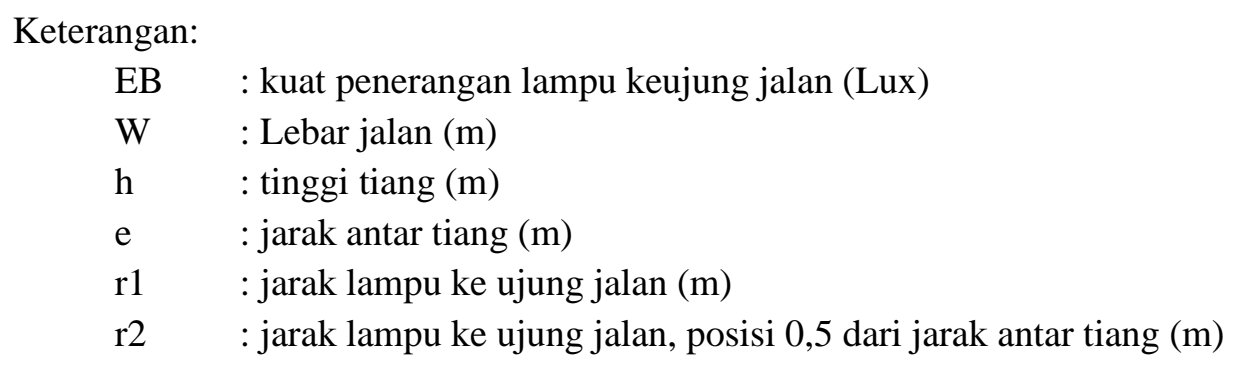

Dengan diketahuinya EB standar penerangan adalah sebesar 15-20 lux (SNI 7391), tinggi tiang dan lebar jalan, maka dapat ditemukan jarak antar tiang dengan cara : 
a. Menghitung jarak lampu ke ujung jalan $\left(r_{1}\right.$ dan $\left.r_{3}\right)$

Dengan diketahui tinggi tiang lampu (h) dan lebar jalan (W) maka dapat diperoleh jarak lampu ke ujung jalan $\left(r_{1}\right.$ dan $\left.r_{3}\right)$ dengan rumus pythagoras sebagai berikut :

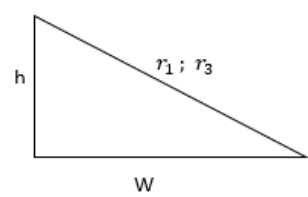

$$
r_{1 ; 3}=\sqrt{h^{2}+W^{2}}
$$

b. Menghitung intensistas penerangan pada lampu (I)

Dengan diketahui EB standar penerangan adalah sebesar 15-20 lux (SNI 7391), tinggi tiang lampu (h), dan jarak lampu keujung jalan $\left(\mathrm{r}_{1}\right.$ dan $\left.\mathrm{r}_{3}\right)$, maka besar intensitas penerangan diperoleh dengan rumus berikut :

$$
I=\frac{E_{B(\text { standar })} x r_{1 ; 3}{ }^{3}}{h}
$$

c. Menghitung jarak lampu ke ujung jalan, posisi 0,5 dari jarak antar tiang $\left(r_{2}\right.$ dan $\left.r_{4}\right)$

Dengan posisi 0,5 dari jarak antar tiang, maka besar kuat penerangan lampu ke ujung jalan adalah $\frac{1}{2} E_{B}$, dikarenakan pada kondisi tersebut

$$
\frac{1}{2} E_{B_{1}}+\frac{1}{2} E_{B_{2}}=E_{B(\text { standar })}
$$

Sehingga :

$$
r_{2 ; 4}=\sqrt[3]{\frac{I h}{\frac{1}{2} E_{B(\text { standar })}}}
$$

Dengan diketahuinya tinggi tiang lampu (h) yang akan digunakan dan besar jarak lampu ke ujung jalan, posisi 0,5 dari jarak antar tiang $\left(r_{2}\right.$ dan $\left.r_{4}\right)$ maka dapat diperoleh nilai $x_{1}$ dan $x_{2}$

$$
x_{1 ; 3}=\sqrt{r_{2 ; 4}^{2}-h^{2}}
$$

Dengan diketahuinya tinggi tiang lampu (h) yang akan digunakan dan besar jarak horizontal lampu ke ujung jalan, posisi 0,5 dari jarak antar tiang $x_{1}$ dan $x_{2}$ maka dapat diperoleh jarak antar tiang dengan rumus sebagai berikut :

$$
e=2\left(\sqrt{x_{1}^{2}-W^{2}}\right)
$$


2. Penentuan jarak antar tiang untuk jalan yang melengkung

a. Penempatan tiang lampu diluar lengkungan jalan

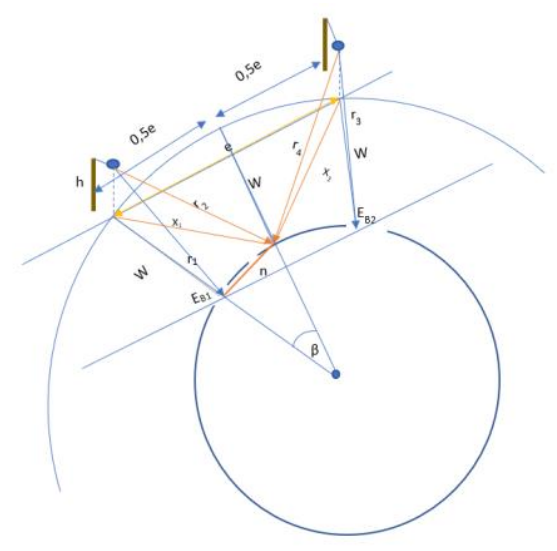

Gambar 3. Perhitungan untuk penentuan jarak antar tiang untuk jalan yang melengkung dengan penempatan tiang lampu diluar lengkungan jalan

Keterangan :

EB : kuat penerangan lampu keujung jalan (Lux)

$\mathrm{W}:$ Lebar jalan $(\mathrm{m})$

$\mathrm{h}$ : tinggi tiang $(\mathrm{m})$

e : jarak antar tiang $(\mathrm{m})$

$\mathrm{r} 1 ; \mathrm{r} 3$ : jarak lampu ke ujung jalan $(\mathrm{m})$

$\mathrm{r} 2: \mathrm{r} 4$ : jarak lampu ke ujung jalan, posisi 0,5 dari jarak antar tiang $(\mathrm{m})$

$\mathrm{R}$ : jari-jari lingkaran jalan (m)

Dengan diketahuinya EB standar penerangan adalah sebesar 15-20 lux (SNI 7391), tinggi tiang dan lebar jalan, maka dapat ditemukan jarak antar tiang dengan cara :

1) Menghitung jarak lampu ke ujung jalan $\left(r_{1}\right.$ dan $\left.r_{3}\right)$

Dengan diketahui tinggi tiang lampu (h) dan lebar jalan (W) maka dapat diperoleh jarak lampu ke ujung jalan $\left(r_{1}\right.$ dan $\left.r_{3}\right)$ dengan rumus pythagoras sebagai berikut :

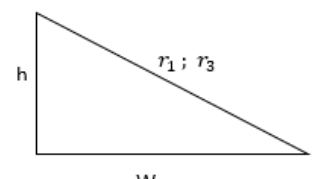

$$
r_{1 ; 3}=\sqrt{h^{2}+W^{2}}
$$

2) Menghitung intensistas penerangan pada lampu (I)

Dengan diketahui EB standar penerangan adalah sebesar 15-20 lux (SNI 7391), tinggi tiang lampu (h), dan jarak lampu keujung jalan $\left(r_{1}\right.$ dan $\left.r_{3}\right)$, maka besar intensitas penerangan diperoleh dengan rumus berikut :

$$
I=\frac{E_{B(\text { standar })} \times r_{1 ; 3}{ }^{3}}{h}
$$

3) Menghitung jarak lampu ke ujung jalan, posisi 0,5 dari jarak antar tiang $\left(r_{2}\right.$ dan $\left.r_{4}\right)$ Dengan posisi 0,5 dari jarak antar tiang, maka besar kuat penerangan lampu ke ujung jalan adalah $\frac{1}{2} E_{B}$, dikarenakan pada kondisi tersebut 


$$
\left.\frac{1}{2} E_{B_{1}}+\frac{1}{2} E_{B_{2}}=E_{B} \text { (standar }\right)
$$

Sehingga :

$$
r_{2 ; 4}=\sqrt[3]{\frac{I h}{\frac{1}{2} E_{B(\text { standar })}}}
$$

Dengan diketahuinya tinggi tiang lampu (h) yang akan digunakan dan besar jarak lampu ke ujung jalan, posisi 0,5 dari jarak antar tiang $\left(r_{2}\right.$ dan $\left.r_{4}\right)$ maka dapat diperoleh nilai $x_{1}$ dan $x_{2}$ :

$$
x_{1 ; 3}=\sqrt{r_{2 ; 4}^{2}-h^{2}}
$$

Selanjutnya untuk mencari besar $\mathrm{n}$, diperoleh dengan rumus berikut :

$$
n=\sqrt{x_{1 ; 3}^{2}-w^{2}}
$$

Setelah diperoleh besar $\mathrm{n}$ maka dapat dicari besar sudut setengah jarak antar tiang ke pusat lingkaran dengan menggunakan rumus tali busur lingkaran sebagai berikut :

$$
\beta=\frac{\text { panjang busur } n \times 360^{\circ}}{2 \pi R_{\text {lingkaran kecil }}}
$$

Jadi untuk menghitung jarak antar tiang lampu dapat dihitung dengan rumus vektor sebagai berikut :

$$
e=\sqrt{R_{\text {lingkaran besar }}^{2}+R_{\text {lingkaran besar }}^{2}-2 \cdot R_{\text {lingkaran besar }} \cdot R_{\text {lingkaran besar }} \cos (2 x \beta)}
$$

3. Penempatan tiang lampu didalam lengkungan jalan

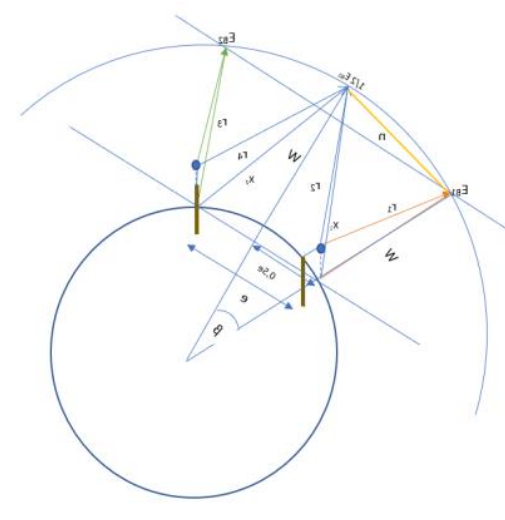

Gambar 4. Perhitungan untuk penentuan jarak antar tiang untuk jalan yang melengkung dengan penempatan tiang lampu didalam lengkungan jalan

Keterangan :

EB : kuat penerangan lampu keujung jalan (Lux)

$\mathrm{W}:$ Lebar jalan (m)

$\mathrm{h}$ : tinggi tiang $(\mathrm{m})$

e : jarak antar tiang $(\mathrm{m})$

$\mathrm{r} 1 ; \mathrm{r} 3$ : jarak lampu ke ujung jalan (m)

$\mathrm{r} 2: \mathrm{r} 4$ : jarak lampu ke ujung jalan, posisi 0,5 dari jarak antar tiang (m)

$\mathrm{R}:$ jari-jari lingkaran jalan (m) 
Dengan diketahuinya EB standar penerangan adalah sebesar 15-20 lux (SNI 7391), tinggi tiang dan lebar jalan, maka dapat ditemukan jarak antar tiang dengan cara :

1) Menghitung jarak lampu ke ujung jalan ( $r_{1}$ dan $\left.r_{3}\right)$

Dengan diketahui tinggi tiang lampu (h) dan lebar jalan (W) maka dapat diperoleh jarak lampu ke ujung jalan $\left(r_{1}\right.$ dan $\left.r_{3}\right)$ dengan rumus pythagoras sebagai berikut :

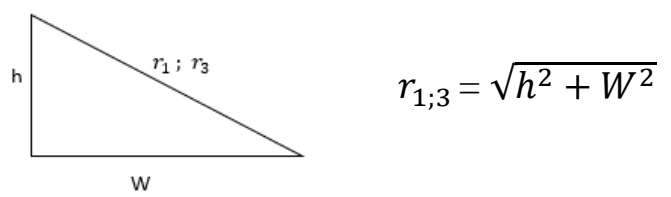

2) Menghitung intensistas penerangan pada lampu (I)

Dengan diketahui EB standar penerangan adalah sebesar 15-20 lux (SNI 7391), tinggi tiang lampu (h), dan jarak lampu keujung jalan ( $r_{1}$ dan $\left.r_{3}\right)$, maka besar intensitas penerangan diperoleh dengan rumus berikut :

$$
I=\frac{E_{B(\text { standar })} \times r_{1 ; 3}{ }^{3}}{h}
$$

3) Menghitung jarak lampu ke ujung jalan, posisi 0,5 dari jarak antar tiang $\left(r_{2}\right.$ dan $\left.r_{4}\right)$ Dengan posisi 0,5 dari jarak antar tiang, maka besar kuat penerangan lampu ke ujung jalan adalah $\frac{1}{2} E_{B}$, dikarenakan pada kondisi tersebut

$$
\frac{1}{2} E_{B_{1}}+\frac{1}{2} E_{B_{2}}=E_{B}(\text { standar })
$$

Sehingga :

$$
r_{2 ; 4}=\sqrt[3]{\frac{I h}{\frac{1}{2} E_{B(\text { standar })}}}
$$

Dengan diketahuinya tinggi tiang lampu (h) yang akan digunakan dan besar jarak lampu ke ujung jalan, posisi 0,5 dari jarak antar tiang $\left(r_{2}\right.$ dan $\left.r_{4}\right)$ maka dapat diperoleh nilai $x_{1} \operatorname{dan} x_{2}$ :

$$
x_{1 ; 3}=\sqrt{r_{2 ; 4}^{2}-h^{2}}
$$

Selanjutnya untuk mencari besar $\mathrm{n}$, diperoleh dengan rumus berikut :

$$
n=\sqrt{x_{1 ; 3}^{2}-w^{2}}
$$

Setelah diperoleh besar $\mathrm{n}$ maka dapat dicari besar sudut setengah jarak antar tiang ke pusat lingkaran dengan menggunakan rumus tali busur lingkaran sebagai berikut :

$$
\beta=\frac{\text { panjang busur } n \times 360^{\circ}}{2 \pi R_{\text {ling karan kecil }}}
$$

Jadi untuk menghitung jarak antar tiang lampu dapat dihitung dengan rumus vektor sebagai berikut :

$e=\sqrt{R_{\text {lingkaran kecil }}^{2}+R_{\text {lingkaran kecil }}^{2}-2 \cdot R_{\text {lingkaran kecil }} \cdot R_{\text {lingkaran kecil }} \cos (2 x \beta)}$ 


\section{Energi dan Kelistrikan: Jurnal Ilmiah}

Vol. 12, No. 2, Juli - Desember 2020, P-ISSN 1979-0783, E-ISSN 2655-5042

https://doi.org/10.33322/energi.v12i2.1063

\section{a. Diagram Alir Penelitian}

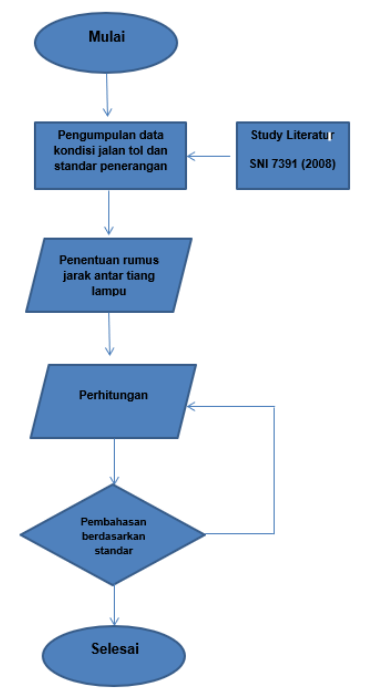

Gambar 5. Diagram Alir Penelitian

\section{HASIL DAN PEMBAHASAN}

\subsection{Penentuan jarak antar tiang untuk jalan yang lurus}

Dengan diketahuinya EB standar penerangan adalah sebesar 15-20 lux (SNI 7391 ; 2008), tinggi tiang dan lebar jalan, maka dapat ditemukan jarak antar tiang dengan rumus sebagai berikut :

$$
e=2\left(\sqrt{x_{1}^{2}-W^{2}}\right)
$$

Diperoleh jarak antar tiang sebagai berikut:

Tabel 1. Tabel perbandingan antara lebar jalan dengan jarak antar tiang sesuai perhitungan, standar dan yang terpasang pada jalan tol

\begin{tabular}{|c|c|c|c|}
\hline $\begin{array}{l}\text { Lebar jalan } \\
\text { (W) } \\
\text { (m) }\end{array}$ & $\begin{array}{c}\text { Jarak antar tiang } \\
\text { perhitungn }(e) \\
(\mathrm{m})\end{array}$ & $\begin{array}{c}\text { Jarak antar } \\
\text { tiang standar } \\
\text { (e) } \\
\text { (m) }\end{array}$ & $\begin{array}{c}\text { Jarak antar tiang } \\
\text { pada jalan tol (e) } \\
(\mathrm{m})\end{array}$ \\
\hline 4,5 & 21,09 & \multirow{23}{*}{$230 \mathrm{~m}$} & \multirow{23}{*}{$30 \mathrm{~m}$} \\
\hline 5,5 & 21,64 & & \\
\hline 6,5 & 22,28 & & \\
\hline 7,5 & 23,00 & & \\
\hline 8,5 & 23,81 & & \\
\hline 9,5 & 24,68 & & \\
\hline 11,5 & 26,60 & & \\
\hline 12,5 & 27,64 & & \\
\hline 13,5 & 28,73 & & \\
\hline 14,5 & 29,85 & & \\
\hline 15,5 & 31,01 & & \\
\hline 16,5 & 32,20 & & \\
\hline 17,5 & 33,41 & & \\
\hline 18,5 & 34,66 & & \\
\hline 19,5 & 35,93 & & \\
\hline 20,5 & 37,21 & & \\
\hline 21,5 & 38,51 & & \\
\hline 22,5 & 39,83 & & \\
\hline 23,5 & 41,16 & & \\
\hline 25,5 & 43,87 & & \\
\hline 28,5 & 48,02 & & \\
\hline 29,5 & 49,41 & & \\
\hline 30,5 & 50,82 & & \\
\hline
\end{tabular}


Berdasarkan hasil perhitungan untuk jalan yang berkisar antara 4,5 m sampai 14,5 m membutuhan jarak antar tiang sebesar 21,09 m sampai 29,85 m. Sehingga apabila dalam penerapan dijalan tol menggunakan keseragaman jarak tiang lampu sebesar $30 \mathrm{~m}$ maka kuat pencahayaan lampu pada jalan tersebut kurang dari standar yang ada.

Sedangkan untuk yang lebar jalan berkisar 15,5 m sampai 30,5 m dari hasil perhitungan membutuhkan jarak antar tiang sebesar 31,01 m sampai 50,82 m, dimana pada penerapan dijalan tol ruas Lingkar Luar Jakarta W2 utara seksi I, jarak antar tiang hanya sebesar $30 \mathrm{~m}$, hal ini mengakibatkan pemborosan dalam hal jumlah tiang lampu yang terpasang.

\subsection{Penentuan jarak antar tiang untuk jalan yang melengkung}

Dengan diketahuinya EB standar penerangan adalah sebesar 15-20 lux (SNI 7391 ; 2008), tinggi tiang dan lebar jalan, maka dapat ditemukan jarak antar tiang untuk jalan yang melengkung dengan penempatan tiang lampu didalam lengkungan jalan dan juga penempatan tiang lampu diluar lengkungan jalan. Sehingga diperoleh rumus untuk jarak antar tiang untuk jalan yang melengkung sebagai berikut :

a. Jarak antar tiang lampu dengan penempatan tiang lampu diluar lengkungan jalan

$$
e=\sqrt{R_{\text {lingkaran besar }}^{2}+R_{\text {lingkaran besar }}^{2}-2 \cdot R_{\text {lingkaran besar. }} \cdot R_{\text {lingkaran besar }} \cos (2 x \beta)}
$$

b. Jarak antar tiang lampu dengan penempatan tiang lampu didalam lengkungan jalan

$$
e=\sqrt{R_{\text {lingkaran kecil }}^{2}+R_{\text {lingkaran kecil }}^{2}-2 \cdot R_{\text {lingkaran kecil }} \cdot R_{\text {lingkaran kecil }} \cos (2 x \beta)}
$$

Setelah dilakukan perhitungan jarak antar tiang lampu terhadap jalan tol ruas Lingkar Luar Jakarta W2 utara seksi I untuk jalan yang lurus didapat :

1. Penempatan tiang lampu diluar lengkungan jalan. Dengan lebar jalan (W) sebesar 7,5 m, diperoleh jarak antar tiang (e) sebesar 25,11 m.

2. Penempatan tiang lampu didalam lengkungan jalan. Dengan lebar jalan (W) sebesar 7,5 m, diperoleh jarak antar tiang (e) sebesar 20,96 m.

Berdasarkan hasil diatas, dapat terlihat perbedaan antara jarak antar tiang dengan penempatan tiang lampu diluar lengkungan jalan dan jarak antar tiang dengan penempatan tiang lampu didalam lengkungan dimana hasilnya untuk penempatan di luar lengkungan jalan lebih besar dari pada didalam lengkungan jalan, hal tersebut berbeda dengan standar yang berlaku pada SNI 7391 (2008) yang dimana hanya menyebutkan jarak antar tiang minimum sebesar $30 \mathrm{~m}$ tanpa mempertimbangkan letak penempatan tiang lampu.

\section{KESIMPULAN DAN SARAN}

\subsection{Kesimpulan}

1. Jalan tol ruas Lingkar Luar Jakarta W2 utara seksi I yang memiliki lebar jalan yang berbeda untuk jalan yang lurus dan juga memiliki sebuah interchange yang melengkung, jarak antar tiang yang digunakan kurang ideal apabila menggunakan jarak antar tiang sebesar $30 \mathrm{~m}$ untuk keduanya.

2. Berdasarkan perhitungan jarak untuk jalan yang lurus dengan lebar jalan berkisar antara 4,5 m sampai 14,5 m membutuhkan jarak antar tiang sebesar 21,09 sampai 29,85 (<30 m) yang mengakibatkan pencahayaan yang kurang dari standar.

3. Untuk yang lebar jalan berkisar $15,5 \mathrm{~m}$ sampai $30,5 \mathrm{~m}$ dari hasil perhitungan membutuhkan jarak antar tiang sebesar 31,01 m sampai 50,82 m (>30 m) yang mengakibatkan pemborosan dalam hal pemasangan jumlah tiang.

4. Untuk jalan yang melengkung dengan lebar jalan sebesar 7,5 m membutuhkan jarak antar tiang sebesar $(<30 \mathrm{~m}$ ) untuk penempatan tiang lampu diluar lengkungan jalan, sedangkan untuk penempatan tiang lampu didalam lengkungan jalan membutuhkan jarak antar tiang yang lebih kecil sebesar 20,96 m $(<30 \mathrm{~m})$. 


\section{Energi dan Kelistrikan: Jurnal Ilmiah}

Vol. 12, No. 2, Juli - Desember 2020, P-ISSN 1979-0783, E-ISSN 2655-5042

https://doi.org/10.33322/energi.v12i2.1063

\subsection{Saran}

Perlu dilakukannya perbaikan dalam hal penentuan jarak antar tiang lampu berdasarkan bentuk jalan dikarenakan penentuan jarak antar tiang sangatlah mempengaruhi kualitas penerangan yang diberikan.

\section{UCAPAN TERIMAKASIH}

Penulis mengucapkan terima kasih kepada PT. Marga Lingkar Jakarta (MLJ) yang telah membantu dalam pelaksanaan pengambilan data penerangan Interchange Jalan Tol Ruas Lingkarluar Jakarta W2 Utara Seksi 1

\section{DAFTAR PUSTAKA}

[1] Badan Standarisasi Nasional, SNI 7391 Spesifikasi Penerangan Jalan di Kawasan Perkotaan, Jakarta : BSN, 2008.

[2] Direktorat Jendral Bina Marga. Direktorat Pembinaan Jalan Kota. 1991. Spesifikasi Lampu Penerangan Jalan Perkotaan. Jakarta: Dirjen Bina Marga, Februari 1992.

[3] Direktorat Jendral Bina Marga Direktorat Pembinaan Jalan Kota. 1990. Panduan Penentuan Klasifikasi Fungsi Jalan di Wilayah Perkotaan. Jakarta: Dirjen Bina Marga, Januari 1990.

[4] https://www.bappenas.go.id/files/rkp/LAMPIRAN\%20PERPRES\%20RKP\%20TAHUN\%202018.pdf

[5] International Commission On Illumination, CIE 180 (2007) Technical Report Road Transport Lighting For Developing Countries.

[6] Asnal Effendi, Aldifian. Perencanaan Penerangan Jalan Umum Jalan Lingkar Utara Kota Solok. Jurnal Teknik Eletro ITP, Volume 2 No. 2, Padang. 2012.

[7] Asnal Effendi, Asep Suryana. Evaluasi Sistem Pencahayaan Lampu Jalan Di Kecamatan Sungai Bahar. Jurnal Teknik Eletro ITP, Volume 2 No. 2, Padang. 2013.

[8] http://www.pelajaran.co.id/2017/25/pen gertian-rumus-dan-contoh-soal- teorema-pythagorasbeserta- pembahasannya.html

[9] Ilyas Achmad Syarifudin, Ir. Bonar Sirait, M.Sc, Dr. Purwoharjono, ST, MT. Rancang Bangun Penataan Lampu Penerangan Jalan Umum Di Kota Sintang. Fakultas Teknik Elektro Universitas Tanjungpura. 